Social Work/Maatskaplike Werk Vol 57 No 1; Issue 7

http://socialwork.journals.ac.za/pub

doi:http://dx.doi.org/10.15270/52-2-909

CASH TRANSFERS AND CAREGIVERS: WORKING TOGETHER TO REDUCE VULNERABILITY AND HIV RISK AMONG ADOLESCENT GIRLS IN JOHANNESBURG, SOUTH AFRICA

Naomi Hill, † Tessa Hochfeld, Leila Patel

In South Africa adolescent girls have the highest HIV incidence of any sex or age cohort. Scalable HIVprevention interventions targeting this group are critical for epidemic control. Reaching 12.2 million children, the Child Support Grant mitigates the socio-structural drivers of HIV risk. This qualitative study of eight adolescents and their caregivers in Westbury, Johannesburg, explored how caregiving increases protective potential. 'Caregiving' enhanced the HIV risk-reduction benefits of 'cash' when characterised by substantial positive caregiver-adolescent involvement and adequate levels of control and consistency. Results underpin the value of social protection as an HIV-prevention modality and endorse investment in caregiver support programmes.

Keywords: adolescent girls, adolescent HIV risk, caregivers, child support grant, cash transfers, vulnerability and HIV risk 


\title{
CASH TRANSFERS AND CAREGIVERS: WORKING TOGETHER TO REDUCE VULNERABILITY AND HIV RISK AMONG ADOLESCENT GIRLS IN JOHANNESBURG, SOUTH AFRICA
}

\author{
Naomi Hill, $†$ Tessa Hochfeld, Leila Patel
}

Ms Naomi Hill, Centre for Social Development in Africa (CDSA), University of Johannesburg, Johannesburg, South Africa; Programme Head, Wits Reproductive Health and HIV Institute (Wits RHI), University of the Witwatersrand, Johannesburg, South Africa.

$\dagger$ Professor Tessa Hochfeld, Centre for Social Development in Africa (CDSA), University of Johannesburg, Johannesburg, South Africa.

Professor Leila Patel, Department of Science and Technology (DST) / National Research Foundation (NRF), South African Research Chair in Welfare and Social Development, University of Johannesburg, Johannesburg, South Africa.

Keywords: adolescent girls, adolescent HIV risk, caregivers, child support grant, cash transfers, vulnerability and HIV risk

\section{INTRODUCTION}

South Africa has the largest human immunodeficiency virus (HIV) epidemic in the world, with an estimated 7.2 million people living with HIV (Joint United Nations Programme on HIV/AIDS, 2018). Adolescent girls and young women (AGYW) bear the highest burden of infection - in the 20 to 24 year age group, HIV prevalence among females $(15,6 \%)$ is three times higher than among heterosexual males (4.8\%) (South African National AIDS Council, 2017). Girls are physiologically at greater risk of HIV infection than males (Centre for Disease Control, 2018) and their vulnerability is compounded by low access to and/or uptake of prevention, testing and treatment services. Because they are less likely to be virally supressed, AGYW may be disproportionately driving new infections. AGYW are particularly vulnerable to the socio-structural drivers of HIV risk, including poverty, under-development, economic inequality, gender inequality and sexual violence (Cluver, Orkin, Meinck, Boyes \& Sherr, 2016; Hardee, Gay, Croce-Galis \& Peltz, 2014; Wamoyi, Mshana, Mongi, Neke, Kapiga \& Changalucha, 2014). Within this context, scalable interventions to reduce adolescent girls' vulnerability to HIV infection are urgently needed.

Growing evidence of the limitations of individually-focused biomedical and behavioural interventions has led to the prioritisation of combination HIV-prevention approaches over the last decade (Hargreaves, Delany-Moretlwe, Hallett, Johnson, Kapiga, Bhattacharjee, Dallabetta \& Garnett, 2016). Such multidisciplinary programmes comprehensively address the biomedical, social and structural forces that drive HIV and serve as barriers to its control. The South African National Strategic Plan on the Prevention of HIV, Sexually Transmitted Diseases and Tuberculosis 2017-2022 defines country-level deliverables required to achieve the global UNAIDS 90-90-90 goals for control of the epidemic (South African National AIDS Council, 2017). It holds the South African National Department of Social Development responsible for addressing the social and structural drivers of HIV with a basket of interventions, including social protection in the form of social grants to the poor. Social work services are thus central to the national HIV response.

While the main aim of social protection has traditionally been the mitigation of economic risk, subSaharan African studies attest to its positive effects on an additional range of social and health indicators (Heise, Lutz, Ranganathan \& Watts, 2013). This focused attention on the potential of social protection to address the economic drivers of HIV as part of combination prevention interventions. Although studies showed that cash transfers lowered HIV prevalence and positively impacted age-disparate sex and 
frequency of sex acts (Baird, Garfein, McIntosh \& Özler, 2012; Pettifor, MacPhail, Selin, GomezOlive, Rosenberg, Wagner, Mabuza, Hughes, Suchindran, Piwowar-Manning, Wang, Twine, Daniel, Andrew, Laeyendecker, Agyei, Tollman, Kahn \& HIV Prevention Trials Network protocol team, 2016), authors concur that the association remains under-explored and the mechanisms through which these programmes work are poorly understood (Kaniki \& Omilola, 2014; Pettifor, Bekker, Hosek, DiClemente, Rosenberg, Bull, Allison, Delany-Moretlwe, Kapogiannis, Cowan \& HIV Prevention Trials Network Adolescent Scientific Committee, 2013; Toska, Cluver, Boyes, Isaacsohn, Hodes \& Sherr, 2017).

The South African Child Support Grant (CSG) is a means-tested monthly cash transfer of R440 to children from birth to 18 years of age living in poor households (South African Social Security Agency, 2020). Evaluation of the CSG showed that social protection leads to improved sexual health outcomes and reduced sexual risk-taking among beneficiaries (Department of Social Development, South African Social Security Agency \& United Nations Children's Fund, 2011). This finding raised the question of whether cash alone is enough to reduce sexual risk-taking. Later empirical testing to determine the protective effects of providing cash and other economic supports such as school feeding, in combination with psychosocial care provisions such as positive parenting, effective caregiver supervision or teacher support, demonstrated that the combination of 'cash plus care' was found to have a cumulative protective effect in reducing HIV-risk behaviours among South African adolescent girls (Cluver, Orkin, Boyes \& Sherr, 2014).

This study aimed to deepen understanding of the ways in which cash transfers and caregiver relations and practices, collectively referred to as 'caregiving', work together to reduce sexual risk behaviours among female adolescents. 'Relations' refers to the reciprocal emotional bond between caregiver and adolescent, and 'practices' to caregiver behaviours towards the young people in their care. The study aligned with the developmental social work approach, recognising the need for micro-, meso- and macro-level interventions (including social protection) to address social challenges (Midgley \& Conley, 2010; Patel, 2015). Developmental social work shapes contemporary South African social welfare policy, of which social protection is a key pillar. The conceptual underpinning of the study was both socio-ecological and positive youth development (PYD). Both resonate with the central tenets of developmental social work theory. The socioecological approach goes beyond an individually-focused understanding of behaviour to consider the bi-directional interplay between the individual and his/her context (contextual dynamics) as well as the socio-structural or environmental determinants of behaviours such as class, race and gender (Bronfenbrenner, 1979; Hargreaves et al., 2016; Wamoyi et al., 2014). These are key influencers of risky sexual behaviours. The PYD approach offers an asset-based conceptualisation of young people, emphasising individual, family and community assets that young people harness to address challenges and reach their potential (Lerner, Lerner \& Benson, 2011). This offered a fresh understanding of how young people engage with risk.

Study objectives were: (1) to investigate perceptions of a small group of female adolescent CSG beneficiaries, aged between 16 and 19 years, and their caregivers, of how caregiver and practices can reduce sexual risk taking; (2) to explore adolescent and caregiver perspectives on how 'cash and care' work together to increase the protective benefits of the CSG, especially in terms of HIVprevention effects, and how protective behaviours emerge; and (3) to make policy and programming recommendations on how social protection (cash) and caregiving (care) can enhance sexual risk-reduction among adolescent girls. Enhanced knowledge about the protective potential of caregiving relations and practices and cash transfers could shape the potential of caregiver strengthening interventions to promote protective behaviours among adolescent girls at risk of HIV infection. 


\section{METHODS}

The study was located at Westbury Secondary School. Westbury is a socially and economically underresourced urban community situated to the west of Johannesburg in South Africa's Gauteng province. The area has a high prevalence of the socio-structural factors associated with adolescent risk-taking, including poverty, crime, gender-based violence and substance abuse (Grobler, 2018; Statistics South Africa, 2018). The economic status of many residents renders them eligible for the CSG.

\section{RESEARCH DESIGN}

The study used a qualitative research design. Knowledge gaps about adolescent risk behaviour are arguably attributable to a scholarly failure to understand adolescent decision-making from the perspective of young people themselves (Booyens \& Crause 2012; Graham, 2015). Understanding behaviour through the participants' subjective worldview and experiences was essential to address the research question investigating 'how and why' caregiving increases the protective potential of the CSG. Given that these questions have not been answered by earlier, predominantly quantitative, studies into risk taking (Cluver, Orkin, Yakubovich \& Sherr, 2016; Toska et al., 2017), a participant-driven qualitative enquiry offered a powerful means of generating new insights into young people's experience. The PYD perspective suggests that qualitative data which places the voices of young people at the centre of the research generates the most meaningful understanding of how they construct and experience life processes (Futch Ehrlich, 2016). In support of the socio-ecological orientation of the study, a qualitative approach facilitates the study of adolescent-caregiver interactions and their interplay with their broader social environments.

\section{DATA GENERATION}

Using school records and her professional judgement, the school's Life Orientation educator purposively selected a sample of eight adolescent girls from the population of 16- to 19-year-old female beneficiaries of the CSG. The selection criteria for inclusion in the study included female learners aged between 16 and 19 years and in receipt of the CSG, either currently or within the last year.

Qualitative enquiry sets out to gain a deep understanding of phenomena experienced by a group of people. It is therefore not possible to determine a priori the sample size that will provide a thorough understanding of the issues under study (Maykut \& Morehouse, 1994). Instead, data were collected until a saturation point was reached - when newly collected data became redundant to data already gathered (Guba, 1989). An adequate quantity of data of sufficient quality was achieved with a study sample comprising eight families $(n=23)$. One dyadic interview did not take place due to the caregiver's work commitments.

Data were generated using in-depth interviews (IDIs). This data-collection method was selected based on the participants' adolescent developmental stage, the sensitive nature of the enquiry and the small sample size. Three separate interview schedules were developed for adolescent girls, caregivers and a dyad comprising the adolescent girl and her caregiver. Dyadic interviews involve a pair of participants who are encouraged to build on each other's comments and expand their coverage of the research topic through sharing and comparing information, thereby offering a genuine sense of how individuals interact with each other (Morgan, Eliot, Lowe \& Gorman, 2016). Adolescents and their caregivers are a naturally occurring pair, making them ideally suited to dyadic interviews. Dyads allowed for a deeper exploration of the relationship dynamics between individual adolescents and their caregivers than would have been possible in individual interviews and a deepening and triangulation of IDI data on caregiving relations. Dependent on participant preference, interviews were conducted in either/both English and Afrikaans.

Two data-elicitation techniques were introduced in an effort to build rapport with the young participants and facilitate exploration of personal and sensitive subject matter. The individual caregiver and adolescent interviews included a vignette; the dyadic interview schedule incorporated a projective relationship mapping exercise to triangulate data collected in the IDI. A vignette is a simulation of real events depicted in hypothetical scenarios (Finch, 1987) - in this case an 18-year-old female adolescent beneficiary of CSG is grappling with issues of concern to the study: caregiver relations, income 
deprivation, partner selection and risky behaviour - which aided exploration of sensitive topics which participants might have been hesitant to broach (Barter \& Renold, 2000). The 'relationship map' technique required each participant in the dyadic interview to create a pictorial representation of their relationship using A4-sized paper and a set of coloured crayons. This prompted the dyad to illustrate easy and difficult aspects of their relationship and positive and negative life experiences, in line with the socioecological concepts of the micro (individual), meso (family, community) and macro (society) levels respectively. Projective techniques were involving and generated respondent curiosity because they were novel and intriguing. They generated insights and ideas that might not otherwise have come to light .

\section{FIGURE 1 \\ QUALITATIVE RESEARCH DESIGN}

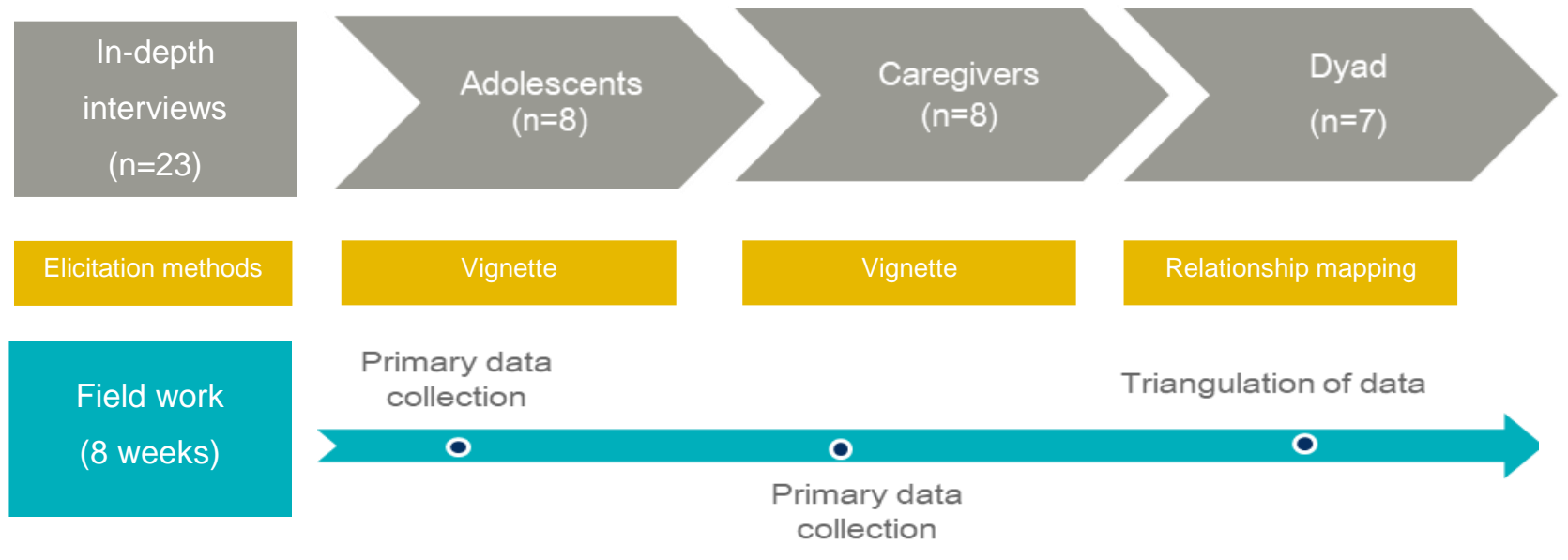

\section{DATA ANALYSIS}

A transcription service provider transcribed and simultaneously translated the Afrikaans audio recordings into English. The researcher listened to all recordings to ensure the accuracy of the translation and transcription. The English transcripts were used for analysis purposes. Data were entered into and thematically analysed using QSR NVivo 12 data-analysis software. The study involved two approaches to coding: inductive coding where themes were drawn from the text, and a priori coding where codes were created before analysis, informed by the study aims and literature review, and applied to the data. Inductive coding is synergetic with the interpretivist perspective as it allows the participants' voices to emerge from the data (Blair, 2015). It is drawn from grounded theory methodology, an approach that allows the researcher to find the answers within the data and develop theory from it, rather than imposing theory onto the data. Answers were found from repeatedly coding, reviewing and refining the coding (Strauss \& Corbin, 1998), "culling for meaning" to capture participants' experience in the process (Maykut \& Morehouse, 1994). The constant comparative method of analysis combines inductive thematic coding with a simultaneous comparison of all units of meaning described (Glaser and Straus, 1967). Each new unit of information was compared with those already coded and grouped accordingly. If there are no similar units of coding, a new code was created.

\section{TRUSTWORTHINESS AND RIGOUR}

The goal of data analysis is to illuminate the experiences of those who lived them by bringing the raw data to life. The study utilised four criteria developed by Guba (1989) for evaluating the trustworthiness of qualitative research. Triangulating the data collected in the individual interviews during the dyadic interviews strengthened the 'credibility' of the findings with the inclusion of participants' judgement of data. The researcher field tested the research tools prior to starting data collection, audio-recorded and transcribed the interviews to ensure detailed and accurate records, and kept field and reflexivity notes to capture the essence of interviews. These measures promoted the 'dependability/auditability' of the data, i.e. the adequacy of the data produced from the research question through the field work to the elucidation of findings. Strategies to ensure 'transferability' of the data included purposive sampling, 'thick' 
description, provision of background to contextualise the study and a detailed account of the methods used. Finally, 'confirmability' or the requirement that findings meet the standards of credibility, dependability and transferability, was supported by electronic and printed version of interviews that allowed for reference to the original data.

\section{ETHICAL CONSIDERATIONS}

The University of Johannesburg's Faculty of Humanities Research Ethics Committee granted ethics approval for the research. The Gauteng Department of Education provided additional authorisation for data collection in the school district. All participants under the age of 18 years signed informed assent and adult participants signed informed consent for interviews. The purpose and nature of the study was carefully explained to all potential participants. In addition to standard concerns regarding participant rights to confidentiality and privacy, ethical considerations in relation to vulnerable minors who are protected under the South African Children's Act No. 38 of 2005 involved (1) not collecting data on sexual behaviour in the dyadic interview in order to protect the adolescent's right to privacy; (2) avoiding any experience of recruitment coercion among beneficiaries of a social grant; and (3) providing counselling referrals on a needs basis. The researcher drew on her professional social work skills to establish rapport with participants and create a climate of safety. Participants received no payment for participating in the study aside from reimbursement for travel expenses.

\section{RESULTS}

\section{Socio-demographic profile}

Participants ranged in age from 16 to 19 years. Except for one adolescent in Grade 11, all were Grade 10 learners. Their caregivers were adult females who were either their mothers (four) or caregiver relatives (three) aged between 35 and 60 years. Relatives had assumed caregiving roles during beneficiaries' infancy or early childhood as a result of divorce in two cases and an AIDS-related death in the third. The marital status of six caregivers was reported as single; one married woman had recently reunited with her husband after a five-year separation. Participants' fathers were both physically and/or emotionally absent. Two of the three adolescents whose fathers were deceased had no information regarding the circumstances of their fathers' deaths. None of the remaining four fathers maintained a close relationship with their daughters, despite living near them in Westbury or neighbouring areas, and only one participant lived with her father.

Caregiver educational status was low; only two participants had completed Grade 12. All caregivers classify as poor as they qualify for income assistance. Three caregivers were in part- or full-time employment in low-skilled jobs such as maintenance or cleaning. The remaining five were largely reliant on social grants. Most households augmented household income and grants with financial support and material contributions from extended family. Only two of the caregivers received intermittent maintenance payments from the biological fathers of their children. Seven of the participants were granted the CSG during infancy; the eighth first received the grant as a pre-schooler. Mothers were the grant recipients in six cases and grandmothers in two. Participants characterised Westbury as a poor living environment with high levels of poverty, substance abuse, crime and violence.

Participants reported having engaged in risky sexual behaviours, or had knowledge of peers who had done so. Risky behaviours included transactional sex, age-discordant sex, sex with multiple partners or casual partners, unprotected sex, and sex while using substances.

Grant utilisation covered household expenditure such as rent, electricity and water, and food; individual purchases covered toiletries (including feminine hygiene products), clothing and school lunches; and limited recreational activities. Some families used the grant to pay school fees. Occasional luxury expenditure by caregivers was limited to meals at a restaurant, a movie or a visit to a shopping mall, and by girls to indulgences such as sweets or highly desired fashion items. The grant had been stopped because of misuse in two cases, and re-instated in the name of a new recipient. 


\section{Perceptions of how caregiver relations and practices can reduce sexual risk taking}

The caregivers in this study demonstrated a range of caregiving relations and practices that can be described as protective, including positive involvement, control and provision of structure (Power, 2013). Findings suggested that as adolescent girls negotiated independence, caregivers were required to maintain a fine balance between autonomy and control in their caregiving relations and practices. This process was complicated by living in a high-risk environment, where adolescents faced real and daily risks to their physical safety and emotional wellbeing.

Practices demonstrating positive involvement were availability, affection and warmth, open communication, praise and encouragement, and support and guidance. Caregivers sought to maintain positive involvement to the best of their ability in the face of the environmental stressors described above.

In terms of availability, caregivers spent time with their wards to the highest degree possible, encouraging a sense of connectedness.

When we are together, wherever, and it's so quiet, the peace of my mother and daughter relationship is very nice. When me and my mother is together, we come away together, we understand each other better. (IDI, adolescent)

This emotional connectedness has been shown to be protective against risky sexual behaviour that can lead to unplanned pregnancy, HIV and other sexually transmitted infections (Wamoyi \& Wight, 2014).

However, most adolescent participants were dissatisfied with the quantity of time they spent with their caregivers, attributing their dissatisfaction to the environmental demands of work, school and household chores. Time constraints, amplified by the competing demands of siblings and other household members, impinged on the quality of relationship time and participants yearned for more meaningful individual interactions with their caregivers:

After school I come home, she maybe be at home or maybe she's at work. And when she's there, she's like busy, she's cooking or she's washing, washing, and she just tells us, "Go do your work". And then we go work and then we don't speak or tell her, "Okay, today my day was ...how it was at school - this happened and things like that." So, we don't get much time. (IDI, adolescent)

A study conducted by Coley, Votruba-Drzal and Schindler et al. (2009) suggested that increases in regular family activities prospectively predicted declines in adolescents' risky sexual activities. The paucity of time participants enjoyed with their caregivers suggests the protective potential of caregiving was limited by circumstances.

Adolescent girls described affection and warmth as loving acts and physical affection.

She just wanna be with me the whole time, she wanna kiss me the whole time - she'll kiss me and say "There is a cool drink, grab the cards. When your homework is done, we will have a game." And then we will sit and laugh and it's just that. (IDI, adolescent)

Open communication emerged as a critical protective feature of caregiving, allowing adolescents a safe space for adolescents to voice their concerns. This was premised by shared time and a loving, trusting relationship, without which adolescents will not be open to guidance:

You spend time with your daughters, they are the people that need us. They need us to discuss things. They need to have relationships with us because they must be able to say, "Ai, I have got this boy, but he doesn't seem to be... ." (IDI, caregiver)

Some caregivers failed to establish or sustain a protective communication style. Here adolescent girls describe their reticence to communicate with their caregivers about risk, at the expense of any protective interaction: 
It's like you're scared to tell her, okay, if you tell your mum, "I had sex and all that", it's gonna be like she's gonna be disappointed in you. She's gonna think to herself, "Why did I do wrong, where did I go wrong, to tell my child, 'Don't do this before your time." (IDI, adolescent)

Praise and encouragement, particularly in relation to school performance, made adolescents feel affirmed and valued:

She will sit with me and speak to me - nice work. I will get an A, the way she speaks to me! (IDI, adolescent)

The praise and encouragement caregivers provided adolescents was a source of motivation to them and resonated with the PYD concept of caregiving as a developmental asset (Lerner et al., 2011).

Participants described their support needs as emotional, financial and practical. Guidance was perceived to include positive role modelling. A sense of disillusionment arose among participants who did not experience strong role models, and whose adult family members held no expectations of them:

Especially when you live in a house where people are doing it in front of you, I don't have somebody to look up to, all the people in my house are on drugs, they are doing all these things and we are still living a poverty life. So why must I still care, I can start at school doing the same things that they are doing because they are not looking, there is no one that I can really look up to in my house. (IDI, adolescent)

Some adolescents were more accepting of advice than others, typically when the caregiver relationship was perceived by the adolescent to be authoritarian and not to allow an age-appropriate degree of autonomy.

She tells me we mustn't walk late, and I mustn't sleep around because I'm going to fall pregnant. It's very odd which I don't want people to tell me what must do, because I know already. (IDI, caregiver)

The findings regarding the various aspects of positive involvement are in line with texts attesting to the beneficial role of parent-child communication on young people's sexual health (Wamoyi et al., 2011) and the impact of family meetings, parent-adolescent communication around sexual topics, family bonding and positive parenting on HIV prevention (Kuo et al., 2016). Amato and Fowler (2002), found optimal parenting demonstrated a high level of support and monitoring, and the avoidance of harsh punishment. This was associated with better school performance, fewer behavioural difficulties, improved mental health, higher levels of social competence and enhanced self-concepts.

With regard to the control aspect of positive caregiver involvement, caregivers saw this as a critical part of their protective role, exercised via monitoring and discipline. These behaviours served the protective function of emotional containment and behavioural regulation. Monitoring was found to occur in five spheres: physical whereabouts and movement; school attendance, homework and scholastic performance; friendships; romantic relationships with the opposite sex; and finance and grant utilization.

Monitoring of young people's physical whereabouts and movements was primarily focussed on curfews, truancy, young peoples' communication regarding their whereabouts, and limiting the use of public transport, notably taxis, to daylight hours. Caregiver rationale for monitoring was heightened by the socio-structural drivers of risk that are present in Westbury, and the adolescent drive in adolescence for autonomy and independence. Second to ensuring the safety of their wards through monitoring their whereabouts, caregivers considered monitoring school performance a critical function. This was protective in that early school leaving is associated with risk (Baird et al., 2012). Caregivers were concerned about the influence of peers and how they might lead their wards into risk. Caregivers expressed concern about their children engaging in romantic relationships and most wanted to delay them if possible.

You should always be on track of the young girls, seeing what the environment is that we are living in. It's drugs, it's prostitutes, it's alcohol, it's everything. So, for me it's important ... because the funny things that are happening, it's really bad. (IDI, caregiver) 
Girls reacted negatively to what they perceived as excessive monitoring and failure to acknowledge independence:

Ja, before I go out, then she always asks me where am I going to, and why am I going there, and what am I going to do there? She asks me all of those questions. And now I don't tell her anymore where I'm going to because she comes there, and I don't like it. (IDI, adolescent)

Frequently used forms of discipline included stonewalling (withdrawal or refusal to communicate), grounding, shouting (including swearing and other verbal abuse), withholding of privileges such as mobile phone or internet access, and corporal punishment, as related by these adolescents. Protective effects emerged when caregivers practised appropriate levels of negotiation with adolescents. Except for one adolescent, none of the participants attested to have any degree of say in the making of rules. This was contradicted by the caregivers, who suggested they exercise a degree of negotiation in determining rules.

Findings showed that caregivers practised levels of discipline and monitoring that have been associated with reduced sexual risk in terms of fewer sexual partners, lower levels of sexual activity, and more consistent condom use (Deptula et al., 2010). The literature suggests that the protective potential of monitoring was optimised when caregivers were able to negotiate expectations and boundaries for behaviour with their wards. This in in line with other studies which suggested that, although caregivers thought strict control was useful, in reality this encouraged adolescents to deceive their parents to avoid conflict with them (Wamoyi et al., 2011).

Themes associated with the third aspect of positive caregiver involvement, namely provision of structure, were a stable, predictable home environment and clear rules. Participants' experiences of stability and predictability in their home environment were reflected in caregivers providing routine.

When I come from school, my mother will always, just before I enter and put down my bag, she will say, "There's your food." Because she knows that I am that person that will come in and say, "What can I eat?", so she will always be there. Make sure I have my food when I come from school, my school clothes must be ready, everything she will see to it. That just shows that she loves me. (IDI, adolescent)

Clear and consistent rules or guidelines pertained primarily to household chores, homecoming times, respect for others' property, boyfriend access to home and prioritisation of schoolwork. However, functioning across different households complicated the application of clear rules.

They can't point at us because we haven't lived with rules and now suddenly there are rules and we have to obey. We haven't stayed with our father, so our mother used to let, okay not let us what we wanna but we were free but now we are not free to do things. (IDI, adolescent)

However, caregiver ability to maintain a consistent, predictable environment with clear rules and boundaries was variable, largely as a result of family dislocation. This resulted in adolescents experiencing confusion and divided loyalties. Second homes were sometimes less functional than primary homes, subjecting the girls to unfavourable experiences such as drug dealing and substance abuse.

I don't know they make me sometimes so confused then this one puts me against my mother, then this one puts me against my granny. Then it's like I want to choose this one and then one says I want to choose my granny or my mother. (IDI, adolescent)

\section{Perceptions of how cash transfers and caregiver practices work together}

The degree to which caregivers were attuned to adolescent developmental needs shaped their ability to engage their wards about grant management in a manner that encouraged the emergence of protective behaviours. Findings were clustered according to three interrelated themes in participants' developmental challenges: autonomy, identity and independence. 
Autonomy related to the growing need for self-governance during adolescence. Some caregivers allowed their wards to manage their own affairs with minimal interference. This dyadic interchange reflects a girl's frustration with her grandmother's perceived failure to recognise her independence, and the more developmentally appropriate response of her primary caregiver.

If they are free, they are not being held tight like my granny she holds you on her pinkie finger, she doesn't want you to do anything you are just stucked up in the house. So that frustrates you. So you need to let her go a little bit, see the outside world a little bit. (IDI, dyad - adolescent)

We want to treat them as kids because we want to keep them there. They grow up but they also need to learn, and my philosophy is you introduce a little bit and if they can handle that then we can go a little bit further until you feel that they can look after themselves.(IDI, dyad caregiver)

Caregiver respect for autonomy is protective in that it allowed adolescents to develop self-regulation. Where the need for independence was acknowledged and negotiated as a legitimate developmental need, there was greater communication, trust and accountability, which was in turn protective.

In the context of the CSG the adolescent quest for independence translates into a desire for increased participation in decision-making. Caregiver attunement to this need facilitated a consultative approach to grant management, which contributed to the development of self-agency, budgeting skills and autonomous decision-making.

These remarks illustrate adolescent experience of (a) consultative and (b) autocratic decision-making in relation to the grant.

So, you should like sit together and decide something you want to do with the money. We must come to an agreement about the money, we are using it together. (IDI, adolescent (a))

She just told me okay, she's gonna give me every month, on the 1st, R150, and then she's gonna take the rest and use it in the house. Then I was like, "No, okay, it's fine." (IDI, adolescent (b))

It is suggested that effective decision-making about money management could enhance financial skills which could improve personal effectiveness. Studies have shown that decision-making capacity in one life dimension supports this competency in other areas (Pettifor, Stoner, Pike, \& Bekker, 2018).

Caregiver responsiveness to the need for autonomy was most clearly demonstrated in the conscious manner they engaged their wards in budgeting processes. Dyadic discussion gives a clear indication of the self-competence that arose from participation in management of the money.

This picture symbolises the brightness on our side, how happy we were to get the money. I also did need this money and I did really use it the right way. I learnt from this money how to work with money. Most times we work well with it." (IDI, dyad - adolescent)

Work sparingly. Try to save as much as possible for the future that is coming for when you really need it. Maybe you need to have an outing, or you get sick and then there is money that can help you get the medication and all that stuff. (IDI, dyad - caregiver)

Another dyadic engagement offered insights into the protective effects of budgeting. The caregiver encouraged her ward to state her needs and actively negotiated expenditure; the adolescent demonstrated how the process encourages her to take responsibility and protect her safety:

Caregiver: Help each other to budget with the things a teenager needs in the house. I think it will help if you like sit down together and work out these things. Because you will find that the child also has that confidence in you to say: "Listen here Ma - this month, I think you only need to take one fifty because the three fifty I need to do this with." She needs to tell me specifically what her needs are because you can tell the child "You can only have a hundred rand this month, I will be taking the three hundred rand", and this is where the children go out and take the risk of getting blessers and things like that. 
Adolescent: That is something good because it just shows you that if my caregiver makes a point to say. "Okay we will sit together, we will do this", so then she is trying her best. So I won't go out and get someone to give me what she can't give me because she is telling me, "Please understand this month if I can't give you this month this amount, just understand next month I will give you the amount that you want." If your caregiver doesn't look after you in the right way, then you won't do things in the right way. (Dyadic interview)

Adolescents acknowledged their need for guidance about grant utilisation and the value of caregiver guidance:

It was the right way she did its cos if I had (total) say I was gonna overuse the money and do all kinds of things (laughter). (IDI, adolescent)

I learnt a lot from my mum on using the money, using it wisely, not using it for stuff that you don't really need. I will use that money wisely now and I will keep my money (to cover my needs). (IDI, adolescent)

When we use the money, I always see what I don't have, and I buy my toiletries. If I see I have extra money left, my change, then I buy something what I need. (IDI, adolescent)

Caregivers who granted their wards a portion of the grant to use independently facilitated their identifying and taking responsibility for their own needs.

Some caregivers considered their ward's developing adult and sexual identities in the manner they managed grant income. Even small monetary contributions towards building a young girl's self-esteem promised to be protective in the face of risky sexual partnerships:

You see I am using the SASSA money is to buy for them clothes and stuff. I take my salary, buy food, like right now I am going to buy the toiletries for her, her pads, shampoo and conditioner, roll-on and face soap and all that. Then I also most of the time buy jewellery and stuff, she wants to look nice and you need to do that.

Interviewer: "Why is it important to do that?"

If you don't, it's pushing the child out the way. That is pushing the child. They will go to other people. (IDI, caregiver)

I would say clothes is very important. Because the kids are very fashion conscious. And hair, the kids - now their hair is a problem for them, you see. You must make your kids happy; you have to do something. On Friday I had a two hundred rand and I wanted to buy myself two tops at sixty rand. When I go to the shop, I didn't buy for myself, I buy her a top. (IDI, caregiver)

Despite their economic and social constraints, adolescents expressed having held positive expectations for their futures. Some caregivers took this into account in budgeting, and some aspired to accumulating modest savings for the future.

Caregiver: There is definitely a need for that money, and I think especially now, it's less than a year she is going to get that grant. We spoke about her doing a short course for nails. We found out the price, it is going to be a couple of thousands. So, as we want to set her up for the future, it is going to cost ...

Adolescent: As she said I need for the courses and the transport and things for me to move forward. Saving some of your money, I think it is important to have some savings of it. Even if it's just a couple of hundred rand that is saved. (Dyadic interview)

\section{DISCUSSION OF KEY FINDINGS}

This study suggests that certain caregiving relations and practices work along with cash to reduce adolescent sexual risk-taking. Findings confirmed evidence that the 'cash' in the form of the CSG together with 'care' in the form of caregiving are more protective than cash on its own. This occurs via 
two pathways: the co-provision of 'cash and care' has a cumulative effect, and caregiver relations and practices in relation to the management of the grant itself can be protective.

Presented as a theory of change, the study's key findings show how 'cash' and 'care' address the structural and behavioural drivers of change ('protection') separately and together, and how developmental, socio-ecological and PYD concepts aid this understanding and support programmatic interventions. Contrary to the concept of 'cash plus care' that dominates current academic and grey literature, the findings suggest that protective benefits lie in 'cash and care'. The two interventions work together - they are more than the sum of their parts - rather than merely being two programmes delivered at the same time (Figure 2).

\section{FIGURE 2 THEORY OF CHANGE}

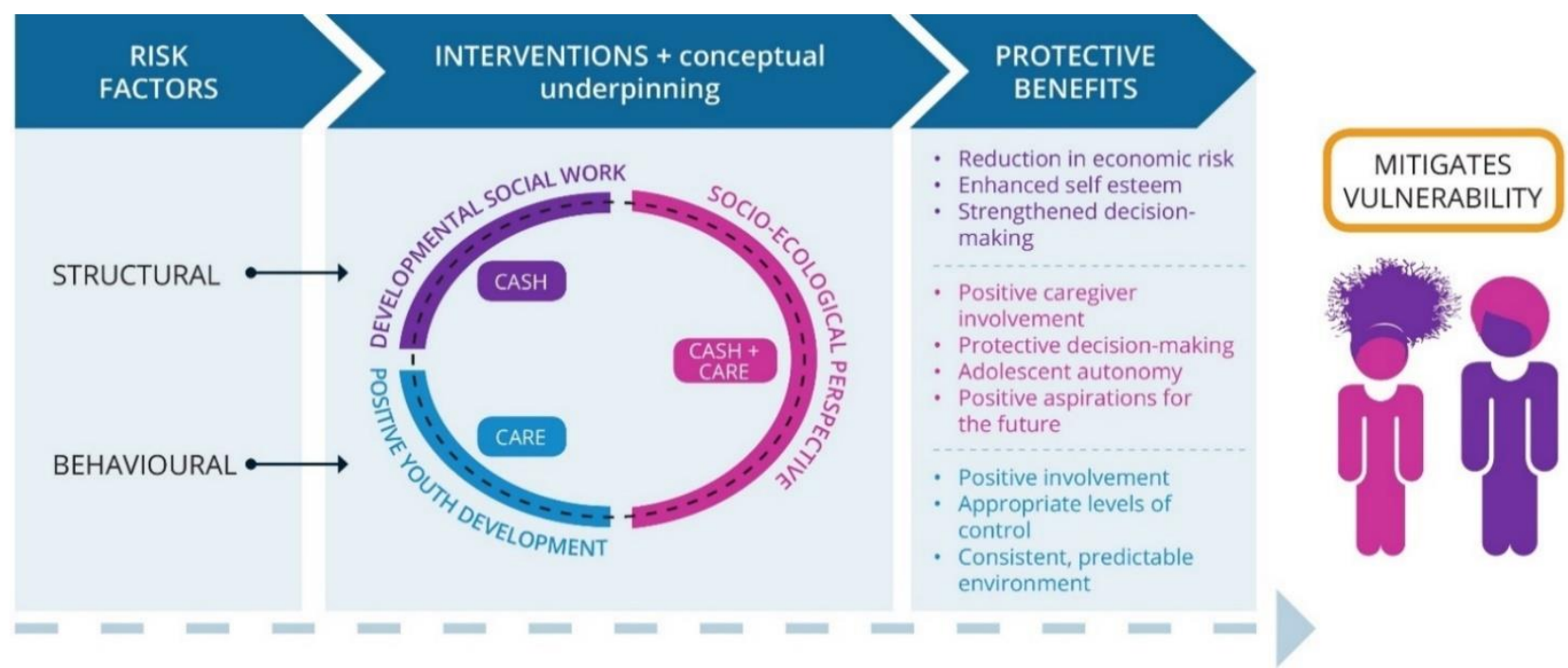

The findings illuminated various environmental factors that impact either positively or negatively on caregiving.

Participant profiles confirmed that CSG recipients experienced significant environmental stressors. They lived in poor, female-headed households in a socio-economically deprived community characterised by multiple socio-structural risk factors. In detailing the economic and behavioural vulnerabilities young girls in Westbury face, the study generated new insights into the intersection of adolescent developmental issues and economic risk; behaviours typically understood to be economically driven, such as transactional and age-disparate sex, were also strongly influenced by emotional drivers such as feeling uncared for at home. The need to experiment, create learning opportunities and act independently of adult authority emerged as key predictors of risk-taking. These findings underscore the proposition that interventions that target the economic drivers of sexual risk behaviours alone will likely be less effective than those which comprehensively address young peoples' economic and emotional needs.

Various caregiver relations and practices shaped the quality of caregiver-adolescent relationships, and thus their protective potential. Firstly, caregivers expressed love, warmth and affection and provided emotional and practical support, even in times of stress. Emotional connectedness has been shown to be protective against risky sexual behaviour that can lead to unplanned pregnancy, HIV and other sexually transmitted infections (Wamoyi \& Wight, 2014). This reflects other findings that adolescents who experience family support, cohesion, connectedness and close relationships are likely to have fewer sexual contacts, engage in less risky sexual behaviours, show increased contraceptive usage and delay sexual debut (Naidoo, Donenberg, Davids, Jonas, Vermaak, Simbayi, Kagee, Ward \& Emersen, 2014). 
Emotional connectedness is foundational for other caregiving practices, including communication about and joint management of the grant. Scarce parental availability because of work and other family commitments reduced the time adolescents spent with their caregivers and hence the opportunity for care and communication. This was a potential risk to the protective aspects of caregiving, as outlines in various texts attesting to the beneficial role of parent-child communication on young people's sexual health (Wamoyi, Fenwick, Urassa, Zaba \& Stones, 2011) and the impact of family meetings, parentadolescent communication around sexual topics, family bonding and positive parenting on HIVprevention (Kuo, Atujuna, Mathews, Stein, Hoare, Beardslee, Operario, Cluver \& K. Brown, 2016).

Secondly, the protective caregiver practice of control, exercised through monitoring and discipline, held potential for a reduction in sexual risk taking. Control was evident in monitoring of young people's whereabouts, their school performance and relationships. Control serves the protective function of emotional containment and behavioural regulation. High levels of environmental risk in Westbury impacted on the monitoring and discipline elements of caregiving, rendering caregivers highly vigilant in order to keep their children safe. Monitoring and discipline were found to be most protective when exercised in an authoritative rather than authoritarian parenting style. The latter resulted in negative reactions from adolescents. Family dislocation or disjointedness caused divided loyalties amongst adolescents torn between two households and negatively on impacted caregiver capacity to consistently apply rules and other parenting practices.

Thirdly, the joint management of grant income with wards instilled decision-making capacity and a sense of agency in adolescents. The CSG afforded caregivers a small degree of financial relief, fostering the protective elements of caregiving such as availability, time and emotional energy, and contributing to opportunities for shared decision-making. Joint management was demonstrated in monthly budgeting and financial planning for the future. Findings suggest that effective decision-making regarding money management will support protective decision-making regarding risk. Studies have proved that decision-making capacity in one life dimension supports this competency in other areas (Pettifor, Stoner, Pike \& Bekker, 2018). Where the need for independence was acknowledging and negotiated as a legitimate developmental need, there was greater communication, trust and accountability, which was in turn protective.

Thirdly, adolescent autonomy is a key 'building block' to the protective effects of care. Consulting with adolescents on how to spend the money and giving them choices results in more appropriate use of the funds, and powerfully reinforces positive involvement. Acknowledging adolescent identity needs, even without significant financial allocation, contributes to adolescents feeling that they are 'seen and heard', which deters them from seeking emotional gratification in risky partnerships. This is substantiated by the socio-ecological and PYD view that adolescent thriving is reliant on an adaptive engagement between the individual and her family, peer group, school and community (Lerner et al., 2011).

Fifthly, caregivers' active support and planning for the future aspirations of adolescents is directly protective, indicating both a belief in the young person's capabilities and the worth of their future goal. Expressed through praise and encouragement, it provides hope and a sense of purpose, and motivates positive behavioural choices. Previous research also showed that positive future expectations promote favourable development and healthier outcomes for youths, but failed to explain the processes through which these benefits are conferred (Stoddard \& Pierce, 2015).

Difficulty in negotiating a degree of autonomy with wards limited the protective effects of caregiving. Those who adopted an authoritarian parenting style alienated young people through autocratic rule-making, physical punishment and excessive monitoring. This diminished adolescents' confidence and led to them to developing avoidance tactics to deceive or evade their caregivers. Some caregivers failed to achieve the emotional connectedness and safety necessary for effective communication about risk. In these instances, communication consisted of projections of their own fears and a set of warnings. These provided to be neither constructive engagements with adolescents' experience nor moulding of more protective behaviours.

In conclusion, the findings support various studies which highlight the complex interplay of relationships between parents and their adolescent children, suggesting that engaged and involved parenting processes may 
serve an important protective role in limiting adolescent engagement in risky sexual activity (Cluver, Meinck, Steinert, Shenderovich, Doubt, Herrero Romero, Lombard, Redfern, Ward, Tsoanyane, Nzima, Sibanda, Wittesaele, De Stone, Boyes, Catanho, Lachman, Salah, Nocuza \& Gardner, 2018; Deptula, Schoeny \& Henry, 2010; Wamoyi, Wight \& Remes, 2015). They corroborate research suggesting that increasing the protective impact of the CSG requires family interventions to support caregiver psychosocial wellbeing, livelihood assistance, access to health and social services, and financial capabilities (Patel, Knijn, GormanSmith, Hochfeld, Isserow, Garthe, Chiba, Moodley \& Kgaphola, 2017).

\section{Strengths and limitations}

This study has several limitations. First, it was conducted with a small sample drawn from one specific neighbourhood and cannot be considered representative of the broader population of CSG recipients and beneficiaries in South Africa. Second, whilst the deputy principal's professional judgement and clear selection criteria mitigated against selection bias, purposive sampling based on the judgement of the researcher/research assistant remains susceptible to bias. This risk was balanced by her knowledge of the girls and balanced by her ability to avoid recruiting girls too vulnerable to participate. Third, the findings reflect the experience of participants historically classified as 'coloured' living in an urban setting and cannot be to transferred other ethnic groups or to rural areas where parenting practices may differ. Replicating this study at other sites with purposively selected samples would address this limitation. Fourth, participants' conscious or unconscious concerns about losing their grants may have led them to elevate its benefits, resulting in influences on their engagement. Similarly, adolescents may have downplayed their accounts of sexual activity or caregivers their harsher caregiving practices to create a positive impression with the researcher. Notwithstanding these limitations, the study provided fresh evidence regarding the potential impact of caregiving and cash transfers on adolescent sexual risk reduction.

\section{Implications and recommendations}

Caregiving is protective, but only if it includes substantial positive involvement along with adequate levels of control and consistency. This underpins the importance of programmes to strengthen caregiving. Such programmes fall within the social work scope of practice, implying a need for improved collaboration between the social work profession and the South African Social Security Agency (SASSA), which administers the CSG. Caregiving practices requiring strengthening are (1) enhancing caregiver- adolescent communication, especially with regard to risk and sexuality; (2) approaches to the control, monitoring and discipline of adolescents, including alternatives to authoritarian communication styles and physical punishment; and (3) dealing with the psychosocial effects of violence, loss and traumatic bereavement.

Support of both the psychosocial wellbeing and parenting skills of caregivers is required to strengthen the protective benefits of caregiving. Caregivers rendered vulnerable by poverty and social inequity have little access to formal psychosocial support services and rely primarily on informal friendship, family and faith-based circles of support. Skilling caregivers in self-care and stress management to enhance psychosocial wellbeing entails enhancing their resilience. Given that young people spend considerable time in school, upskilling of teachers in psychosocial support approaches will increase the level of 'care' recipients of the CSG receive. It is recommended that social workers provide school-based caregiver-teacher-adolescent programmes to increase the level of care provided to CSG beneficiaries.

Including financial planning skills as part of caregiver strengthening initiatives could reduce the misuse of grant income and maximise its protective effects. Skilling peer educators to provide educational communication at DSD and SASSA offices and pay points offers a cost-effective means to change grant-management practices. Additional recommendations include digital screening of caregiver strengthening material in the waiting rooms of the DSD and the South African Social Security Agency (SASSA) offices; making available informational materials for dis tribution at DSD offices and SASSA pay points; and setting up mobile communication platforms to reach all recipients 
of the CSG with messaging on optimal grant utilisation, risk-reduction messaging and positive parenting guidance.

Caregiver programmes developed for facilitation by the various cadres of an expanded health and social development workforce in addition to professionals - community health workers, community caregivers, social auxiliary workers, early childhood development practitioners, and child and youth care workers and leveraging the capacity of existing family strengthening programmes will best achieve scale and saturation of programme content.

Additional research is required to fully understand the effects of caregiver strengthening programmes on risk reduction. The family and school are the most proximal environments influencing adolescent behaviour. Future research is indicated into the role of the school/teachers in providing the 'care' aspect of social protection. An evaluation of the impact of caregiver-teacher-adolescent workshops on grant utilisation and risk will yield insights into how to expand the 'care' component of 'cash plus care'. Caregiving is not uniform across cultures. Replicating the study in, for example, rural, black African communities would provide further data on the socio-cultural influences of caregiving, thereby strengthening more evidence-informed family support programming.

Acknowledgements - The first author is thankful to the adolescent girls and their caregivers who entrusted her with their life stories and generously gave of their time. The staff of Westbury Secondary School willingly supported study implementation, despite a busy teaching schedule. The first author benefited enormously from the support of her supervisors at the Centre for Social Development in Africa at the University of Johannesburg, Professors Leila Patel and Tessa Hochfeld, and acknowledge their contribution. Professor Tessa Hochfeld sadly passed away before the publication of this article.

\section{REFERENCES}

AMATO, P., \& FOWLER, F. 2002. Parenting practices, child adjustment and family diversity. Journal of Marriage and Family, 64: 703-716.

BAIRD, S. J., GARFEIN, R. S., MCINTOSH, C. T. \& ÖZLER, B. 2012. Effect of a cash transfer programme for schooling on prevalence of HIV and herpes simplex type 2 in Malawi: A cluster randomised trial. The Lancet, 379: 1320-1329.

BARTER, C. \& RENOLD, E. 2000. 'I wanna tell you a story': Exploring the application of vignettes in qualitative research with children and young people. International Journal of Social Research Methodology, 3: 307-323.

BLAIR, E. 2015. A reflexive exploration of two qualitative data coding techniques. Journal of Methods and Measurement in the Social Sciences, 6: 14-29.

BOOYENS, M. \& CRAUSE, E. 2012. Excluded from education and work: Perceptions of at risk youth. Social Work/Maatskaplike Werk 48(4): 255-274.

BRONFENBRENNER, U. 1979. The ecology of human development: Experiments by nature and design. Cambridge, MA: Harvard University Press.

CENTRE FOR DISEASE CONTROL. 2018. HIV Risk Behaviours Atlanta, USA: Centre for Disease Control. [Online] Available: https://www.cdc.gov/hiv/risk/estimates/riskbehaviors.html [Accessed 22/01/ 2018].

CLUVER, L., MEINCK, F., STEINERT, J. I., SHENDEROVICH, Y., DOUBT, J., HERRERO ROMERO, R., LOMBARD, C. J., REDFERN, A., WARD, C. L., TSOANYANE, S., NZIMA, D., SIBANDA, N., WITTESAELE, C., DE STONE, S., BOYES, M. E., CATANHO, R., LACHMAN, J. M., SALAH, N., NOCUZA, M. \& GARDNER, F. 2018. Parenting for lifelong health: a pragmatic cluster randomised controlled trial of a non-commercialised parenting programme for adolescents and their families in South Africa. BMJ Glob Health, 3: e000539. 
CLUVER, L., ORKIN, F., BOYES, M. \& SHERR, L. 2014. Cash plus care: Social protection cumulatively mitigates HIV-risk behaviour among adolescents in South Africa. AIDS, 28: S389S397.

CLUVER, L., ORKIN, F., MEINCK, F., BOYES, M. \& SHERR, L. 2016. Structural drivers and social protection: Mechanisms of HIV risk and HIV prevention for South African adolescents. Journal of the International AIDS Society, 19: 20646.

CLUVER, L., ORKIN, F., YAKUBOVICH, A. \& SHERR, L. 2016. Combination social protection for reducing HIV-risk behaviour among adolescents in South Africa. Journal of Acquired Immune Deficiency Syndrome, 72: 96-104.

COLEY, R. L., VOTRUBA-DRZAL, E. \& SCHINDLER, H. S. 2009. Fathers' and mothers' parenting predicting and responding to adolescent sexual risk behaviours. Child Development, 80: 808-827.

DEPARTMENT OF SOCIAL DEVELOPMENT, SOUTH AFRICAN SOCIAL SECURITY AGENCY \& UNITED NATIONS CHILDREN'S FUND 2011. Child support grant evaluation 2010: Qualitative research report. Pretoria: UNICEF South Africa.

DEPTULA, D. P., SCHOENY, M. E. \& HENRY, D. B. 2010. How can parents make a difference? Longitudinal associations with adolescent sexual behaviour. Journal of Family Psychology, 24: 731739.

FINCH, J. 1987. The vignette technique in survey research. Sociology, 21: 105-114.

FUTCH EHRLICH, V. A. 2016. The promise of qualitative methods for expanding theories of positive youth development. Qualitative Psychology, 3: 2-6.

GRAHAM, L. 2015. Understanding risk in the everyday identity-work of young people on the East Rand. Johannesburg: University of Johannesburg. (Doctoral dissertation)

GROBLER, R. 2018. 'Gangsters, here we come!' - Police minister launches task team in Westbury. News 24, 22 October.

GUBA, E. G., \& LINCOLN, Y. S. 1989. Fourth generation evaluation. Newbury Park, CA: SAGE Publications.

HARDEE, K., GAY, J., CROCE-GALIS, M. \& PELTZ, A. 2014. Strengthening the enabling environment for women and girls: What is the evidence in social and structural approaches in the HIV response? Journal of the International AIDS Society, 17: 18619.

HARGREAVES, J., DELANY-MORETLWE, S., HALLETT, T., JOHNSON, S., KAPIGA, S., BHATTACHARJEE, P., DALLABETTA, G. \& GARNETT, G. 2016. The HIV prevention cascade: Integrating theories of epidemiological, behavioural, and social science into programme design and monitoring. The Lancet HIV, 3: e318-e322.

HEISE, L., LUTZ, B., RANGANATHAN, M. \& WATTS, C. 2013. Cash transfers for HIV prevention: Considering their potential. Journal of the International AIDS Society, 16: 18615.

JOINT UNITED NATIONS PROGRAMME ON HIV/AIDS. 2018. South Africa: Overview. [Online] Available: http://www.unaids.org/en/regionscountries/countries/southafrica [Accessed 15/08/ 2018].

KANIKI, S. \& OMILOLA, B. 2014. Social protection in Africa: A review of potential contribution and impact on poverty reduction. South Africa: United Nations Development Programme.

KUO, C., ATUJUNA, M., MATHEWS, C., STEIN, D., HOARE, J., BEARDSLEE, W., OPERARIO, D., CLUVER, L. \& K. BROWN, L. 2016. Developing family interventions for adolescent HIV prevention in South Africa. AIDS Care, 28: 106-110. 
LERNER, R., LERNER, J. \& BENSON, J. B. 2011. Positive youth development: Research and applications for promoting thriving in adolescence. In: LERNER., R., LERNER., J. \& BENSON., J. (eds). Advances in Child Development and Behavior: Volume 41. Positive youth development San Diego, CA: Elsevier Academic Press.

MAYKUT, P. \& MOREHOUSE, R. 1994. Beginning qualitative research: A philosophical and practical guide. London: The Falmer Press.

MIDGLEY, J. \& CONLEY, A. 2010. The theory and practice of developmental social work. In: MIDGLEY, J. \& CONLEY, A. (eds). The theory and practice of developmental social work: Theories and skills for developmental social work. Oxford: Oxford University Press.

MORGAN, D. L., ELIOT, S., LOWE, R. A. \& GORMAN, P. 2016. Dyadic interviews as a tool for qualitative evaluation. American Journal of Evaluation, 37: 109-117.

NAIDOO, P., DONENBERG, G., DAVIDS, A., JONAS, K., VERMAAK, R., SIMBAYI, L., KAGEE, A., WARD, C. \& EMERSEN, E. 2014. Exploring risk and protective mechanisms associated with HIV infection among adolescents in South Africa. Journal of Psychology in Africa, 24: 232-240.

PATEL, L. 2015. Social welfare and social development. Cape Town: Oxford University Press.

PATEL, L., KNIJN, T., GORMAN-SMITH, D., HOCHFELD, T., ISSEROW, M., GARTHE, R., CHIBA, J., MOODLEY, J. \& KGAPHOLA, I. 2017. Family contexts, child support grants and child well-being in South Africa. Johannesburg: Centre for Social Development in Africa, University of Johannesburg.

PETTIFOR, A., BEKKER, L. G., HOSEK, S., DICLEMENTE, R., ROSENBERG, M., BULL, S. S., ALLISON, S., DELANY-MORETLWE, S., KAPOGIANNIS, B. G., COWAN, F. \& HIV PREVENTION TRIALS NETWORK ADOLESCENT SCIENTIFIC COMMITTEE 2013. Preventing HIV among young people: Research priorities for the future. Journal of Acquired Immune Deficiency Syndrome, 63 Suppl 2: S155-60.

PETTIFOR, A., MACPHAIL, C., SELIN, A., GOMEZ-OLIVE, F. X., ROSENBERG, M., WAGNER, R. G., MABUZA, W., HUGHES, J. P., SUCHINDRAN, C., PIWOWAR-MANNING, E., WANG, J., TWINE, R., DANIEL, T., ANDREW, P., LAEYENDECKER, O., AGYEI, Y., TOLLMAN, S., KAHN, K. \& HIV PREVENTION TRIALS NETWORK PROTOCOL TEAM 2016. HPTN 068: A randomized control trial of a conditional cash transfer to reduce HIV infection in young women in South Africa Study design and baseline results. AIDS Behaviour, 20: 1863-82.

PETTIFOR, A., STONER, M., PIKE, C. \& BEKKER, L. G. 2018. Adolescent lives matter: Preventing HIV in adolescents. Current opinion in HIV and AIDS, 13: 265-273.

SOUTH AFRICAN NATIONAL AIDS COUNCIL 2017. National Strategic Plan on HIV, STIs and TB 2017-2022. Pretoria: South African National AIDS Council.

STATISTICS SOUTH AFRICA 2018. Mid-year population estimates report. Pretoria: Statistics South Africa.

STODDARD, S. A. \& PIERCE, J. 2015. Promoting positive future expectations during adolescence: The role of assets. American Journal of Community Psychology, 56: 332-341.

STRAUSS, A. \& CORBIN, J. 1998. Basics of qualitative research: Techniques and procedures for developing grounded theory. Thousand Oaks, CA: SAGE Publications.

TOSKA, E., CLUVER, L. D., BOYES, M. E., ISAACSOHN, M., HODES, R. \& SHERR, L. 2017. School, supervision and adolescent-sensitive clinic care: Combination social protection and reduced unprotected sex among HIV-positive adolescents in South Africa. AIDS Behavior, 21: 2746-2759. 
WAMOYI, J., FENWICK, A., URASSA, M., ZABA, B. \& STONES, W. 2011. Parental control and monitoring of young people's sexual behaviour in rural North-Western Tanzania: Implications for sexual and reproductive health interventions. BioMed Central Public Health, 11: 106-106.

WAMOYI, J., MSHANA, G., MONGI, A., NEKE, N., KAPIGA, S. \& CHANGALUCHA, J. 2014. A review of interventions addressing structural drivers of adolescents' sexual and reproductive health vulnerability in sub-Saharan Africa: Implications for sexual health programming. Reproductive Health, 11: 88-88.

WAMOYI, J. \& WIGHT, D. 2014. 'Mum never loved me.' How structural factors influence adolescent sexual and reproductive health through parent-child connectedness: A qualitative study in rural Tanzania. African Journal of AIDS Research, 13: 169-178.

WAMOYI, J., WIGHT, D. \& REMES, P. 2015. The structural influence of family and parenting on young people's sexual and reproductive health in rural northern Tanzania. Culture, Health \& Sexuality, 17: 718-732. 